\title{
Fuller Albright 1900-1969
}

\section{Helen Thomopoulou*}

Fuller Albright (F.A.) was born on January $12^{\text {th }}$ 1900 in Buffalo N.Y. into a very wealty family. His father donated the Albright Memorial Library Building in Scranton Pennsylvania and the Albright Museum in Buffalo and was a benefactor to many other institutions.

In 1920, F.A. entered Harvard Medical School, and graduated in 1924. He then worked as an intern at the Massachusetts General Hospital (M.G.H.) in the Department of Dr. J. Aub and W. Bauer where he was initiated into the field of the parathyroid glands and calcium metabolism. In 1927 and 1928, at Johns Hopkins Hospital in Baltimore, Albright together with Dr. R. Ellsworth studied and published a case of idiopathic hypoparathyroidism, the first in the bibliography. He subsequently spent two years in Vienna studying under Dr. J. Erdheim, an authority on parathyroid diseases. He was he who, in 1906, established the relationship between the parathyroid glands and calcium metabolism and who first described compensatory hyperplasia of the parathyroids following osteomalacia. F.A, always held him in deep respect. On his returm from Vienna F.A., went to M.G.H. where he stayed as Associate Professor in Medicine until the end of his life.

During his productive life, F.A. with his collaborators published a total of 111 papers. Following his death, another 13 papers where added. The main subject was parathyroid glands, bones and stones, (fiftyeight papers in total, out of which 17 papers were pub-

Address correspondence and requests for reprints to: Helen Thomopoulou, 21 Vas. Sofias Ave., 10674 Athens, Greece

Received 06-02-02, Revised 30-03-02, Accepted 07-05-02

*Harvard Research Fellow (1951-1953) Mass. General

Hospital, Dr F. Albright's Unit. lished during the first years of his career in 1929-1937).

In 1930, he studied the osteitis fibrosa cystica, in 1936 the renal osteitis fibrosa cystica and in 1937, vitamin D resistance and rickets. In 1937-38, he published a paper entitled "Osteitis fibrosa with pigmentation and gonadal dysfunction". In 1942, he published his research on pseudohypoparathyroidism, the Seabright-Bantam syndrome and in 1952, he discovered pseudo-pseudo-hypoparathyroidism.

However, F.A.'s interest was not confined to the parathyroid glands. Starting as far back as 1935, remarkable work was produced by him concerning the gonads. In 1941, together with H. Klinefelter and E.S. Reifenstein, he described the homonymous syndrome characterized by gynecomastia, aspermatogenesis without aleydism and increased excretion of FSH. In 1942, F.A. studied and elucidated the syndrome described by Turner in his paper "A syndrome characterized by primary ovarian deficiency and short stature" where he measured the elevated FSH. Beginning in 1940 and for the following seven years, he worked on postmenopausal osteoporosis and its treatment with oestrogens as well as on Paget's disease and its treatment with oestrogens.

The pituitary was the subject of his studies starting in 1948. Among other achievements, he developed a biological method to measure FSH in urine. He also set the basis for population control by administering oestrogens and progesterone to inhibit ovulation in cases of dysmenorrhea. Finally in 1954, together with Ann Forbes et al, he described the galactorrhea syndrome attributing it to "some pituitary hormone that produces amenorrhea and galactorrhea and low FSH".

The adrenal glands were Fuller's favoured subject of research. He studied Cushing's syndrome attributing it to the "sugar hormone" of the adrenals. He also 
worked on the adrenogenital syndrome and used cortisone as a treatment.

There are also numerous papers by him concerning a broad spectrum of subjects such as his method to measure FSH in urine, the mesurement of steroids in urine, the effects of proteins in osteoporosis, e.t.c.

It was Fuller Albright who, in 1947, invented the end organ unresponsiveness on pseudo-hypoparathyroidism. He writes "We thought the primary disturbance was a failure of response to some hormone by the end organ. Another probable example of failure of the end organ to respond is met within patients with low basal metabolic rate without other evidence of hypothyroidism ... still another example is the absence of a beard in the American Indians".

As already mentioned, F.A. was the first to apply oestrogens with progesterone to inhibit ovulation thus making him a pioneer of the contraceptive pill.

Three of his publications are legendary:

- Some of the do's and dont's in clinical investigation

- Common sense in Endocrinology.

- Diseases of the ductless glands

At least eight previously unknown diseases or syndromes were discovered and described by F.A.

Fuller Albright was a man of high intelligence, inventive, intuitive, flexible in thought and at the same time practical, eminently pragmatic and full of humor. He was a thoroughly engaging and charming man whose radiant personality entirely overshadowed his physical disability.

He would work on what he called a "working hypothesis", i.e a preconstructed hypothesis ready, as he said, to abandon it "without previous notice". A favored maxim of his was "measure something" and another "look at all sides".

F.A. never used statistics saying "Statistic are important, but I don't trust them". He was not a man of "big" numbers. He prefered "small" numbers, deep study and a sound analysis of the data. On the other hand, he was very keen on graphics. Everything was put on paper as bars, lines, arrows, even as landscapes, birds or animals. Dr Means used to say that Fuller's figures reminded one of St. Sebastian's martyrdorm because of the many arrows they contained.

Fuller Albright was a generous man. There was a cabinet unlocked with programs for future investigations. F.A. used to say: "Ideas we have, time we have not to realize them. If someone can profit from them he is welcome".

Being the inventive person as he was, he knew how to ovecome any obstacle. When he had no laboratory method, he invented a clinical solution, for instance measuring the weight of the axillary hair.

There were moments of awe and astonishment for us. I was present when in front of a battery of bone $x$ rays he uttered the word pseudo-pseudo-hypoparathyroidism. To our question: "What is that". Fuller unperturbed said: "it is a new syndrome".

In 1936 F.A. developed the symptoms of Parkinson's disease. He lived with his disease, in fact ignoring it, until 1956. He then decided to submit to brain surgery. The result was that he remained in a vegetable condition for 13 years until his death on December $8^{\text {th }} 1969$.

Here ends the story of a unique man, one of the founders of the $20^{\text {th }}$ century endocrinology. All of us and many more who had the privilege to meet him and/or work with him will treasure his memory forever in our mind and heart. 